\title{
2-D georesistivity structure in the central part of the northeastern Japan arc
}

\author{
Yukio Fujinawa ${ }^{1}$, Noriaki Kawakami ${ }^{2}$, Jun Inoue ${ }^{2}$, Theodore H. Asch ${ }^{2}$, Shinji Takasugi ${ }^{3}$, and Yoshimori Honkura ${ }^{4}$ \\ ${ }^{1}$ National Research Institute for Earth Science and Disaster Prevention, Tennohdai 3-1, Tsukuba-shi, Ibaraki 305-0006, Japan \\ ${ }^{2}$ Geothermal Energy Research and Development Co., Ltd., 11-7, Kabuto-cho, Nihonbashi, Chuo-ku, Tokyo 103-0026, Japan \\ ${ }^{3}$ Geothermal Engineering Co., Ltd., 804, Koami-cho, Nihonbashi, Chuo-ku, Tokyo 103-0016, Japan \\ ${ }^{4}$ Tokyo Institute of Technology, Ookayama 2-12-1, Meguro-ku, Tokyo 152-8551, Japan
}

(Received November 4, 1998; Revised September 8, 1999; Accepted September 10, 1999)

\begin{abstract}
Wide-band (0.002 20,000 Hz) magnetotelluric measurements (MT) observations have been conducted along three traverses in the central Tohoku district of the northeastern Japan arc at 86 observation sites since 1990 in order to image the electrical resistivity structure. We used the impedance tensors fully corrected for the three-dimensional galvanic distortion effects including static shift effects in order to refine previous 2-D models (discussed in Fujinawa et al., 1997). The subsurface 3-D effects are found to be generally small with the result of a slight difference between the present model and the previously reported one.

The modeling results indicate that the crust is homogeneous without an enhanced conductivity zone in the lower crust, in general agreement with results in the northern part of the Tohoku district. The refined resistivity profiles delineate more clearly two near-surface conductive anomalies located in the fracture zone between the Dewa Hill and the Central Basin Range, and in the zone between the Kitakami and Abukuma River regions. Conductors in the crust west of the Sekiryo Mountain Range generally correlate well with mapped faults or pre-Tertiary tectonic lines. Several buried faults are also suggested from the conductivity data. The electrical resistivity distribution and known active faults are integrated to better understand the seismo-tectonics and geologic regime associated with the subduction processes in the Japan arc region.
\end{abstract}

\section{Introduction}

Knowledge of the georesistivity distribution may be helpful for understanding tectonic processes including associated seismicity and regional metamorphic activity. Combined use of georesistivity data with other geophysical data such as gravity, geomagnetism, and deformation parameters is essential to reveal the geological regime in the crust and upper mantle. The Tohoku area with both active volcanic and seismic activity is located in northeastern Japan arc where the Pacific plate subducts beneath the European plate. The structure of the crust in the region has been investigated using seismic and electromagnetic approaches since 1990 (Yokokura et al., 1992; Fujinawa et al., 1997) to construct a geodynamic model of the island arc. The present study is concerned with the electromagnetic measurements. The geological and tectonic setting in this region can be seen in Fujinawa et al. (1997) and Ogawa (1992), and a historical background of MT surveying in northeast Japan is discussed in previous reports (Fujinawa et al., 1997).

It was revealed that there are prominent conductors around the Central Basins and the east of the Central Mountain Ranges in the central part of the Tohoku district. The 2D models presented there did not, however, reflect corrections for 3-D subsurface heterogeneity effects. These were shown to be rather small but could not be totally neglected

Copy right $(\mathrm{C}$ The Society of Geomagnetism and Earth, Planetary and Space Sciences (SGEPSS); The Seismological Society of Japan; The Volcanological Society of Japan; The Geodetic Society of Japan; The Japanese Society for Planetary Sciences.
(Kawakami et al., 1997) using the Groom-Bailey Decomposition (GBD) method (Groom and Bailey, 1989, 1991; Groom et al., 1993).

In this report we present 2-D models using the impedance tensors fully corrected for the galvanic distortion effects at each site determined by the GBD procedure taking into account the gain factor. The TEM (Transient ElectroMagnetic) method (Sternberg et al., 1988) is adopted to infer the site gain factor, which can not be obtained directly by the GBD technique. We limit our investigation to 2-D modeling in this report; 3-D modeling is not treated but will be reported in future.

In northeastern Japan there is an extensive seismic network which has been developed by Tohoku University (e.g., Hasegawa et al., 1991). This network provides detailed knowledge of regional seismicity including the depths of the Conrad and Moho Discontinuities (Horiuchi et al., 1982a,b; Zhao et al., 1992a). The structure of the subducted Pacific Plate (Umino and Hasegawa, 1975) and the seismic velocity structure (Hasemi et al., 1984; Obara et al., 1986; Zhao et $a l ., 1992 b$ ) could also be delineated. These seismic structures could be more clearly interpreted if the regional georesistivity structure can be used, especially because the georesistivity is known to be sensitive to interstitial pore water and to partial melting of rock, which are important factors in the earthquake occurrence. The conductivity of the lower crust is of particular interest because the seismicity in the region is almost confined to the upper crust. 
(a)

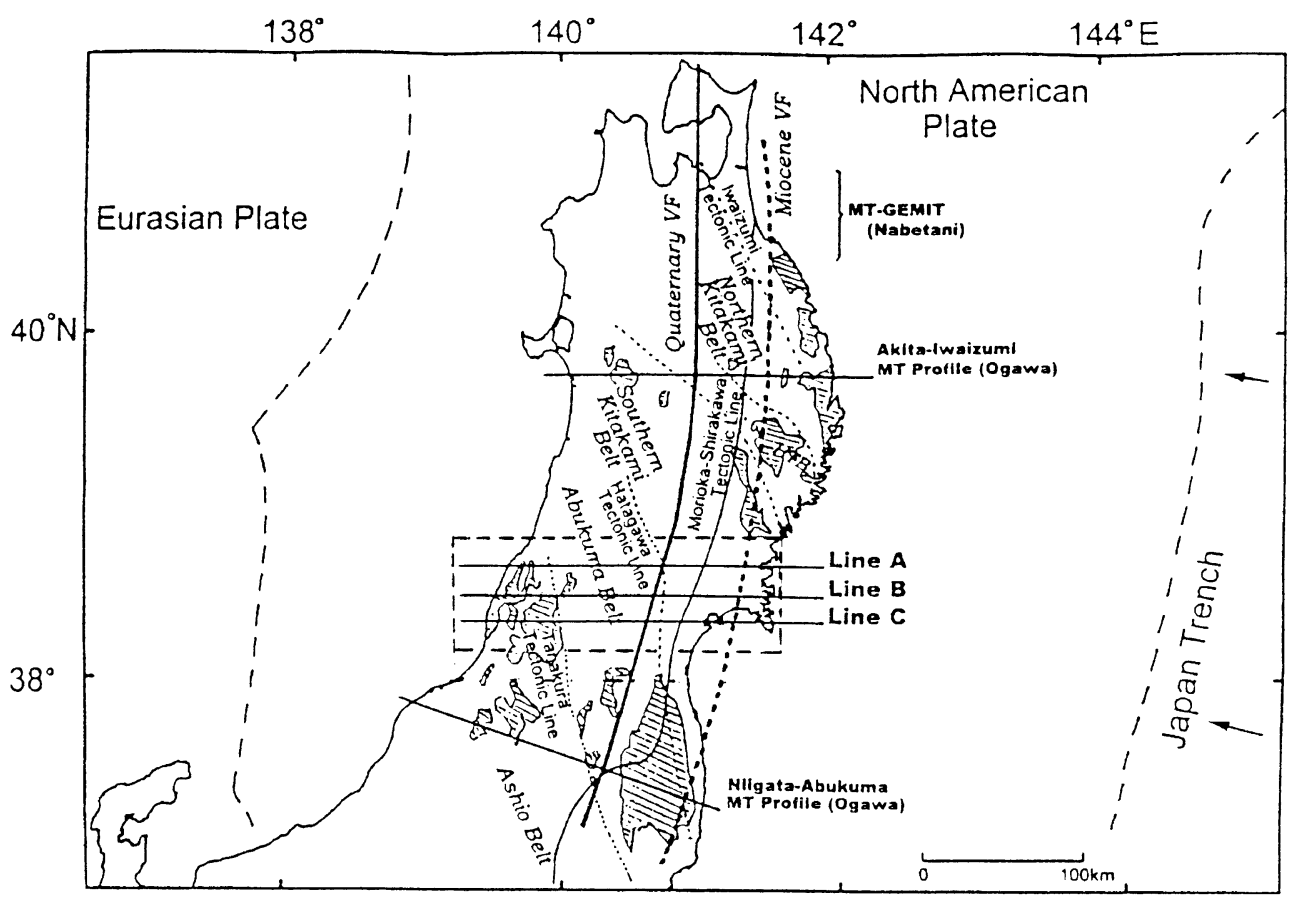

(b)

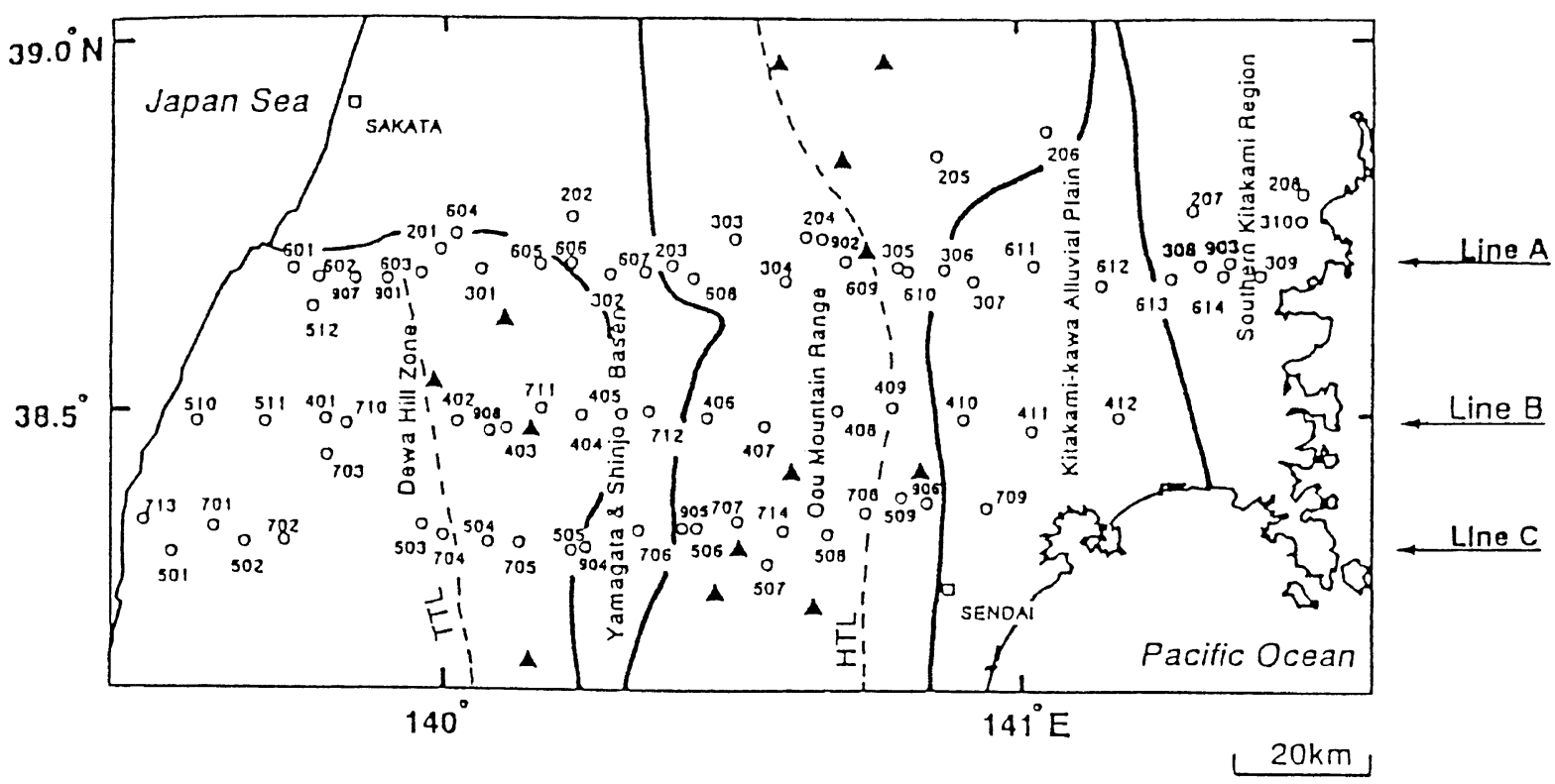

Fig. 1. (a) Simplified geological maps of the northeast Japan arc in the pre-Tertiary and the three MT profiles, Lines A, B, and C (Fujinawa et al., 1997). Miocene and Quaternary volcanic fronts are shown with several tectonic lines. The MT transects north of the present study area (Akita-Iwaizumi) and south of the present study area (Niigata-Abukuma) surveyed by Ogawa (1992) are shown. The northernmost parts have been surveyed by Nabetani and his group (e.g., Nabetani, 1992); (b) Location of the MT measurement sites (Line A: +, Line B: *, Line C: X) and geologic divisions (After Geological Survey of Japan, 1995). Triangles denote Quaternary volcanoes. TTL is the Tanakura tectonic line and HTL is Hatagawa tectonic line. TEM measurement was also conducted at each site. 


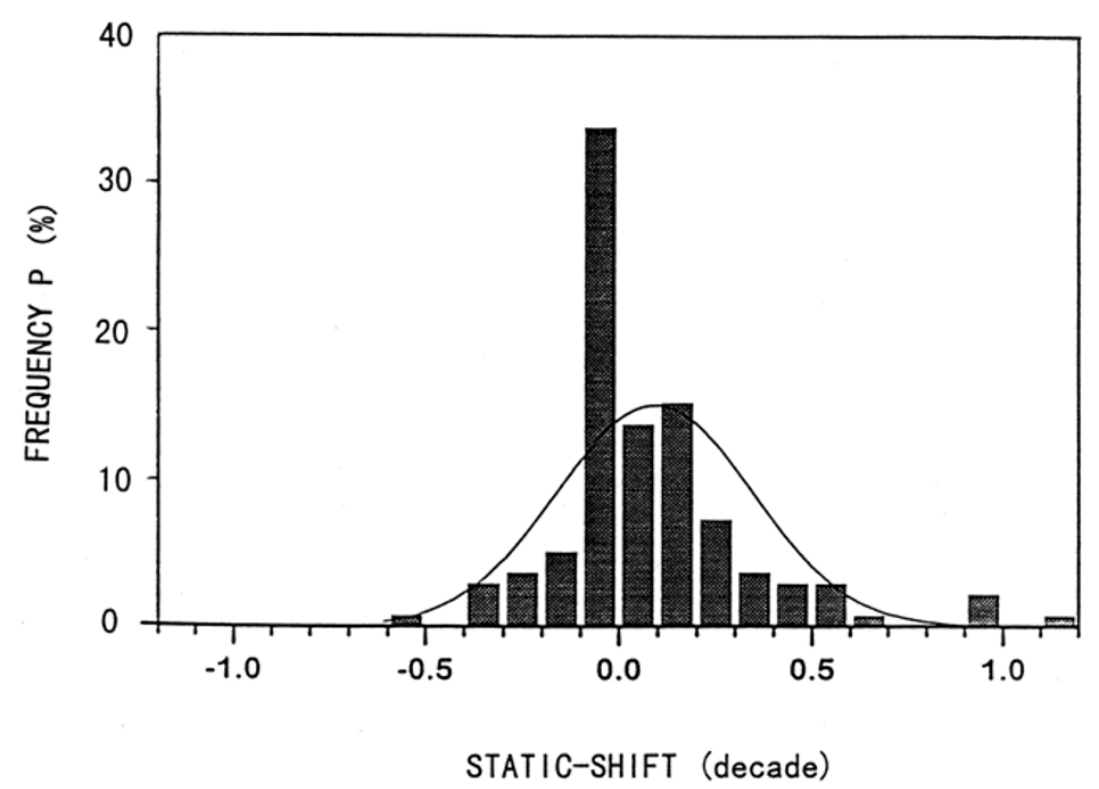

Fig. 2. Histogram of the static-shifts estimated by the TEM observations at all the MT points except four sites where TEM measurements could not be successfully conducted or the merging of the MT and TEM data was not successful.

\section{Observation and Data}

The survey design and measurement procedures are described in Fujinawa et al. (1997). The previous model used broadband magnetotelluric data acquired at 78 observation sites in the central part of the northeastern Japan arc along over three traverses (Lines A, B, and C from north to south) (Fig. 1). The magnetotelluric observations were conducted at 37, 19, and 22 sites each on Lines A, B, and C, respectively. A total of eight observation sites were added after the previous report in order to investigate in more detail possible conductive bodies indicated previously and to check the plausibility of localized conductive anomalies which appeared only at some isolated sites on the profiles. The standard remote reference technique of Gamble et al. (1979) was adopted in order to improve the quality of the acquired MT data. Data quality is generally good in the mountaneous area, but not in urban areas along the eastern heavily populated plain area. Several steps to improve data quality were taken besides the remote reference technique, such as smoothing of the impedance tensor in the frequency domain through the 1-D Bostic model as in previous report. The smoothed impedance data are sampled at chosen frequencies on the basis of the 1-D model.

In the tensor distortion analysis the site gain factor related to the static-shift caused by charge accumulation at boundaries can not be calculated during the GBD procedure, and so needs to be inferred by some other means. In this study, a time-domain em measurement method (Sternberg et al., 1988) was applied to handle MT static-shifts (Jiracek, 1990), utilizing a TEM-FAST ProSystem (AEMR Co., Ltd.). A coincident in-loop TEM measurement was made using a rectangular antenna configuration with total length $200-300 \mathrm{~m}$. A longer loop was used when the $\mathrm{S} / \mathrm{N}$ ratio was too low at sites with high resistivities to provide sufficiently small error bars for the longest time intervals of data acquisition.

The apparent resistivity was calculated through the late- time asymptotic response (Spies and Eggers, 1986). Onedimensional analysis of the TEM data was used to obtain layered models of the shallow depths. This provides an independent estimation of the apparent resistivity and phase at the higher MT measurement frequency bands. A frequency distribution of the TEM apparent resistivities and phases were merged with the MT measurements for both the orthogonal TE and TM modes. Considerable scatter of data of the MT apparent resistivity and phase led us to adopt frequency domain averaging to get plausible static-shifts. At two of the MT sites, the TEM and MT phase curves do not match well with the result of failure to estimate the static shifts by this method.

Calculated static shifts are shown in Fig. 2 for the TE and TM modes. The amount of shifts turned out to be less than 0.2 decade for $70 \%$ of the data. The simple mean of the absolute value of the shift $\bar{S}=0.084$ decade and the standard deviation $\sigma=0.24$ decade. Range of the estimated static shifts is generally in accord with that reported by Meju (1996) at more than a hundred sites in spite of the variety of geologic regime at observation area. It is therefore suggested that the previous 2-D MT resistivity model (Fujinawa et al., 1997 ) is not very different from the "real" image. Some sites, however, exhibit large shifts of a decade or more, and indicate that the static shift corrections should be used in the modeling.

\section{Subsurface Distortions}

It has been demonstrated that the electrical resistivity structure in the survey region is nearly two-dimensional (Fujinawa et al., 1997; Kawakami et al., 1997). Moreover, the effect of subsurface 3-D heterogeneities have been quantitatively estimated by means of the Groom-Bailey tensor decomposition method, or GBD (Groom and Bailey, 1989, 1991; Groom et al., 1993). This practical technique provides a "corrected" two-dimensional impedance $Z_{2 \mathrm{D}}$ from 
the observed impedance tensor $Z_{o b}$. The GBD decomposition procedure provides values for regional strike direction $\phi$, thrust $t$, and shear $e$ but not site gain $g$. The site gain was determined by using the result of the TEM.

The decomposition analysis was applied to the whole data including new data acquired at sites designated as the 900 series $\left(9^{* *}\right.$ in Fig. 1). The GBD method indicated that the 3-D heterogeneity effect at major sites could be reasonably described as the 3-D galvanic distortion over the 2-D inductive structure. The estimated regional strike direction was distributed around north-northwest to south-southwest with considerable deviation at several sites. And the strike correlates well with that of the geological units and the axis of the island arc, though a little bit inclined toward west (Kawakami et al., 1997). At several sites the GBD result shows that the 3-D effects are not consistent with the assumed 3-D galvanic distortions with a considerable 3-D structure at depth having large skew angles (Kawakami et al., 1998). Those sites reveal that the GBD-indicated structural trend of the Neogene units being nearly parallel to the trench axis are different from the trend of the pre-Tertiary basement rock units (Kimura et al., 1991). Results of 2-D modeling should be treated carefully in the interpretation beneath those sites at depth of the lower crust and upper mantle. Those 3-D induction features can only be treated using the 3-D modeling result, which belongs to a theme of a future report.

\section{2-D Modeling}

Considering the considerable scatter in the strike direction ensemble in the GBD analysis, we assume, for simplicity, that the regional strike in the 2-D modeling is N-S, as in the previous report by Fujinawa et al. (1997). The 2-D MT inversion algorithm, GRRI (Lee et al., 1995; Yamane et al., 1996), was applied to this data as in the previous analysis. The algorithm is an extension of the RRI algorithm, developed by Smith and Booker (1991). Possible effects of the Pacific Ocean and the Japan Sea are considered by assuming surface zones $50 \mathrm{~m}$ deep with resistivities of $0.2 \mathrm{ohm} . \mathrm{m}$ (salt water) out from the coast and adjacent to the regional profiles. All of the free inversion parameters are the same as in the previous study except those of the modeling mesh.

The final 2-D models along the three traverses are presented in Fig. 3. The earthquake hypocenters through the seismic network of Tohoku University are overlain. Here the TM-mode models are only displayed though we obtained the 2-D models for the TM, TE, and joint modes. The TM mode inversions resulted in 2-D models that fit the observed data at almost all sites along the three traverses over the specified frequency range (Fig. 4(a)). Figure 4(b) shows the apparent resistivity and phase data corresponding to observed raw data at the transect B. Here error bars denoting 50\% confidence limit at the whole sites on line B can be seen in Fig. 4(b) (symbol ]).

The convergence in inversion is judged rather subjectively based on the fit of the model data to the observed data as well as on overall smoothness of the model. The observed data and the calculated values along the three lines are shown in Fig. 4(a). Generally, there is a good fit by the models to the data though there are several sites with a large degree of misfit over certain frequency bands, and increased misfit in comparison with the previous model (Fujinawa et al., 1997) at several sites.

Inverting the TE mode, however, resulted in a quite different model compared with the TM model, though the fit of the model to the data is satisfactory at most of sites. We could not succeed in getting a model consistent with that obtained for the TM mode, in spite of many trials with different mesh design, deletion of neighboring sites with large differences (contrasts) in apparent resistivity, or even supplementing the data set with additional synthetic sites near the problematic locations. Therefore, the TE modeling is set aside in this paper as a subject for future investigation.

The following is a comparison of the 2-D models from the present study using $Z_{2 \mathrm{D}}$ and those from Fujinawa et al. (1997) constructed using the "uncorrected" data $Z_{o b}$. We now have more reasonable 2-D models of the region in the sense that the impedance tensors are of a 2-D structure. New models are found to be very similar with old ones in spite of usage of corrected impedance data and a larger dataset with addition of eight new sites. Two prominent conductive bodies, CB around the Central Basin (around Sites 605-203), and KK, east of the Central Mountain Range around the Kitakami River (around the sites 306-612), appear to be nearly the same as in the previous model. It is possibly because effects of the static-shifts are not meaningfully large under the condition of the smoothness constraint adopted, and because the impedance tensors at additional sites are not so much different from those at neighbouring sites used in the previous model.

Along Line A Fujinawa et al. (1997) presented an localized conductive anomaly in the Central Mountain Ranges (Sekiryou: SE) under Site 204, which has little similarity with sorrounding sites. The anomaly was suggested not to be a numerical modeling artifact, but a local heterogeneity related to geothermal activity at a nearby Quaternary volcano. In order to test this hypothesis, supplemental MT data were acquired at Site 902 which is just east of Site 204 (Fig. 1). The apparent resistivity profile at Site 902 turned out to be very similar to those at Sites 304 and 609 which do not have the prominent conductive anomaly. Thus the data at Site 204 was discarded in the present 2-D modeling investigation.

Another conductive anomaly (PC) located near the Pacific coast, around Sites 308 and 309, was discussed in some detail in Fujinawa et al. (1997). In order to resolve the problem additional data were acquired at Site 903 near the conductive anomaly PC. The resulting model does not indicate a strong conductor in this region though there appears to be a small conductive body. We can conclude that the PC anomaly is not real, but induced by possible 3-D effects and by inclusion of data from Site 308 of fair quality. Weakly conductive bodies extending from the middle crust down to Moho depths under Sites 611 and 612 near KK, however, are probably not real because the models obtained by using a finer mesh in the upper crust did not include these conductors. They may possibly be caused by inappropriate mesh design.

The presence of the apparent conductor (JP) located near the Japan Sea under Site 602 (Fujinawa et al., 1997) was checked for with the addition of two new sites, 901 and 907 between Sites 601 and 603. The 1-D models for the new dataset indicate that the region around Site 901 is nearly the 

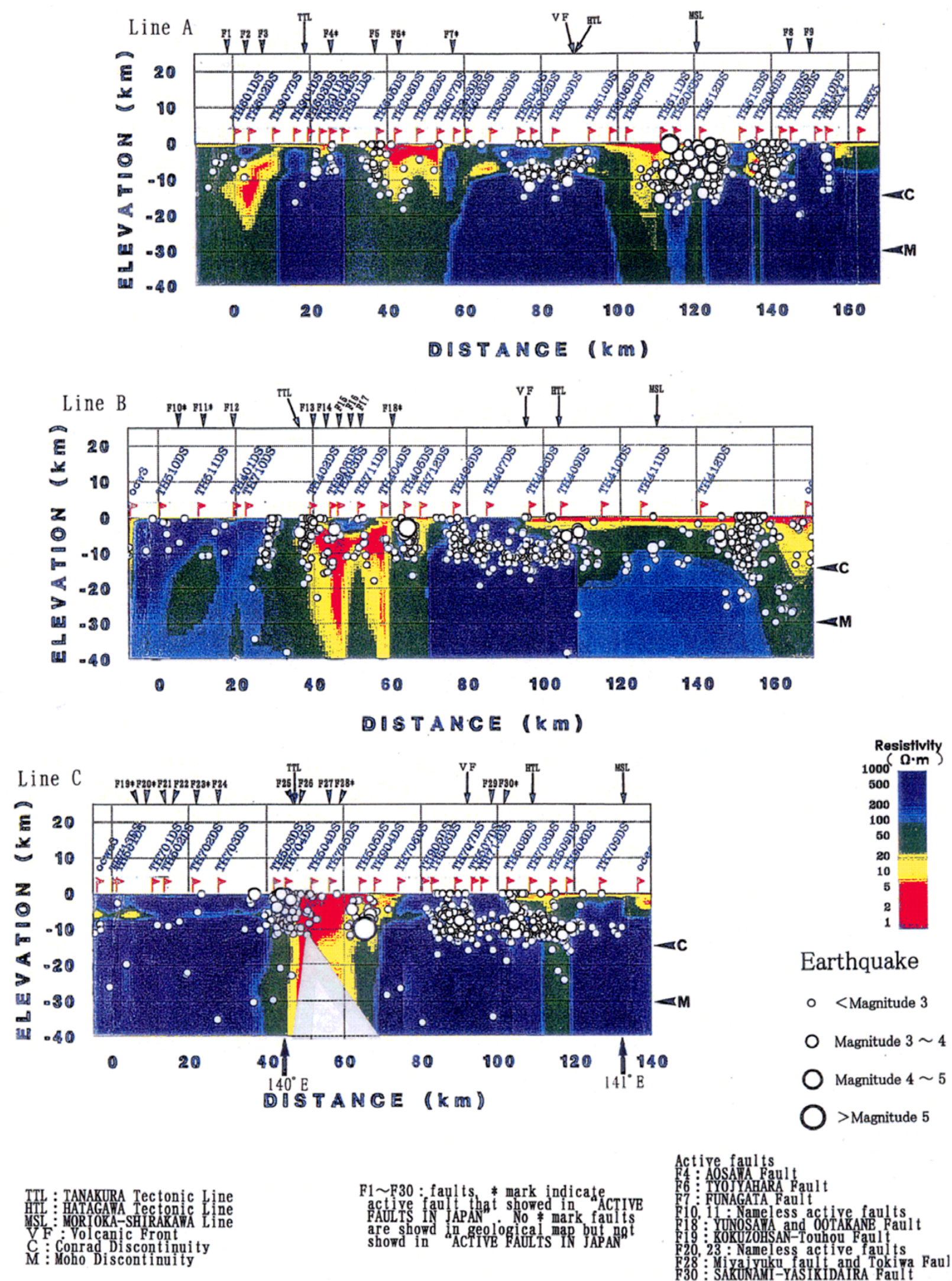

Fig. 3. Two-dimensional resistivity models for the TM mode along the three transects using "corrected" impedance tensors. Earthquake hypocenters determined by Tohoku University are overlain with active faults $\left(\mathrm{Fi}^{*}\right)$ and geological lineaments $(\mathrm{Fi})$. 

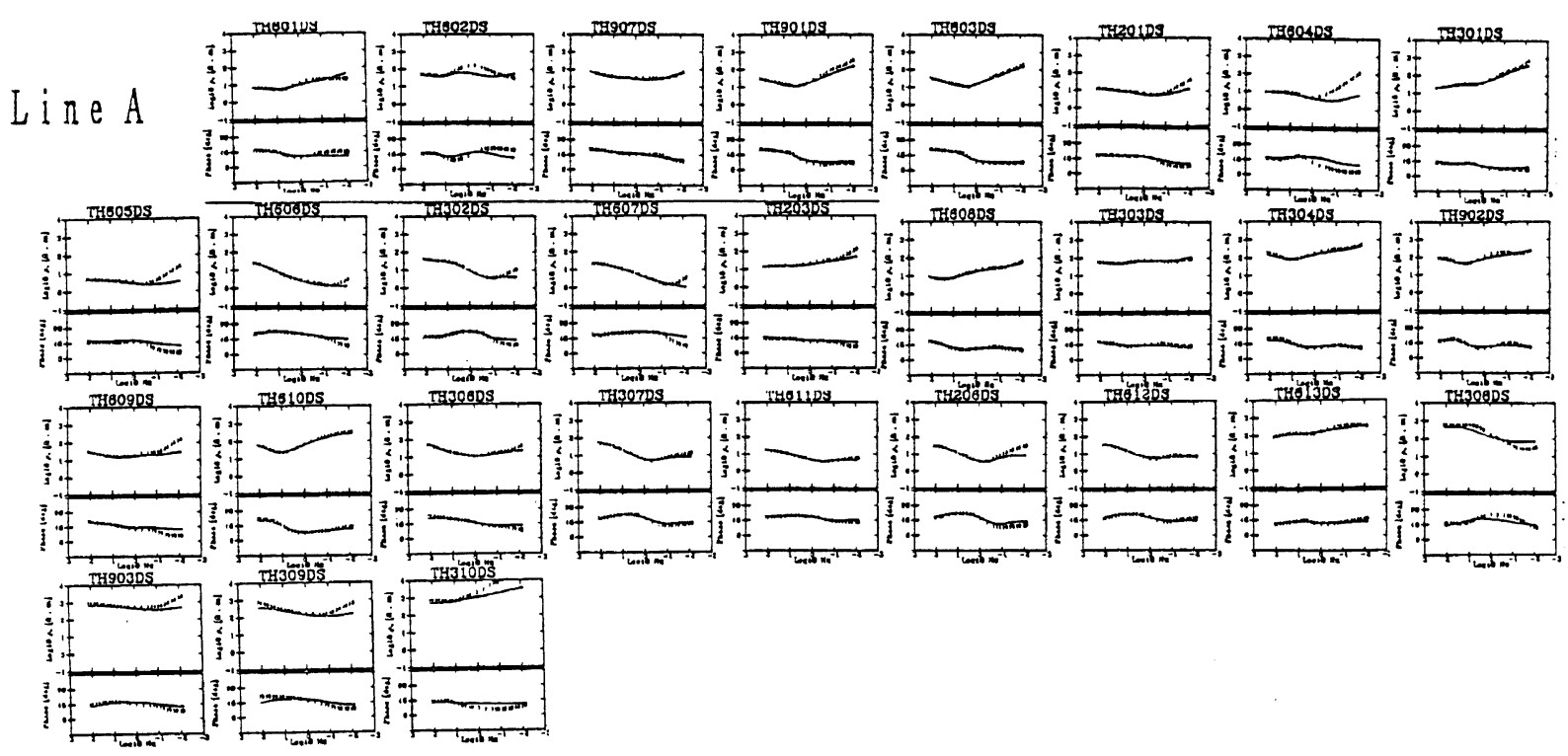

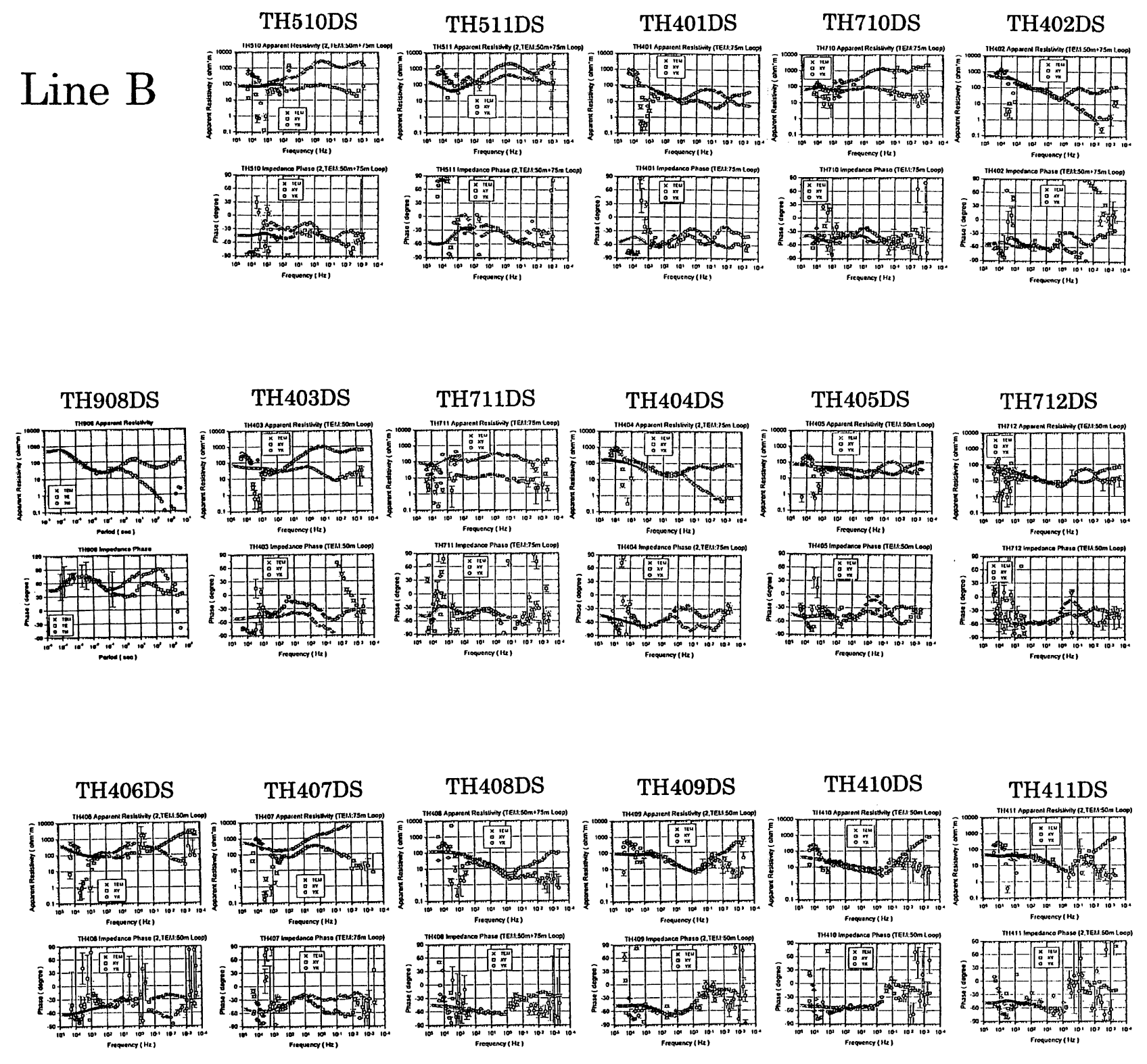

TH412DS
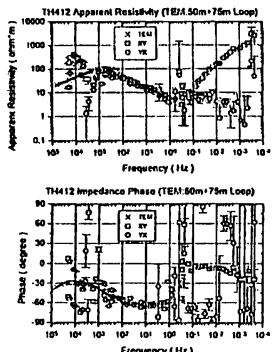

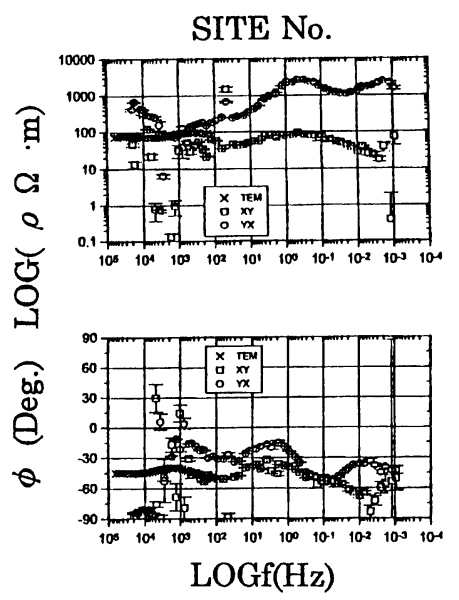

Fig. 4(b). Raw apparent resistivity and phase for two orthogonal components at transect B with coordinates in the directions NS-EW. 
same as that of its easterly neighbor, Site 603, and that Site 907 is in a transition zone between the neighboring regions. Experiments in the course of searching reasonable models through the inversion suggested that the vertical striping is caused by either severe 3-D heterogeneities or by inappropriate mesh design. Using a finer modelling mesh in the near-surface resulted in a conductor that is less than about $1 \mathrm{~km}$ in thickness compared with the case shown in Fig. 3 extending downward several kilometers in depth. Therefore, we can assume that there is a conductive body in the upper crust and possibly another conductive body near the Conrad Discontinuity under Site 602.

In Line B only Site (908) was added on this line between Sites 402 and 403, near the conductive body CB. The present model for Line B, presented in Fig. 3, is almost the same as that in Fujinawa et al. (1997). This is possibly due to a small 3-D heterogeneity effect around this area. There are two prominent conductors in this region: a thin, wide subsurface conductor east of the Central Mountain Range between Sites 408 and 412, and a very prominent conductor west of the Central Mountain Range between Sites 402 and 404. The latter was erroneously described in Fujinawa et al. (1997) as under the Yamagata basin. This conductor (CB) probably corresponds to an extensive fracture zone west of the Yamagata Basin, as presented in Figs. 1 and 3.

The upper part of the Yamagata basin is characterised by a thin conductor with a thickness less than $1 \mathrm{~km}$ (see Fig. 3). A very shallow conductor can be seen under Site 712, both in the present model and in the previous study. The vertical striping of the western conductive anomaly CB appearing in the model may be a numerical artifact. We can not, however, deny the possibility of a vertical extension of the conductive signature corresponding to major faults extending deeper than the Conrad discontinuity. We note the similarity with the deep penetration of a fracture zone found in western Quebec (Calvert et al., 1995; Tournerie and Chouteau, 1998) though caution is needed in making this comparison because of the different tectonic regimes in the two regions.

A resistive region in the upper crust west of the conductive fracture zone is thought to correspond to plutonic rocks around Mt. Asahi. It is to be noted that the lower crust in this region is relatively more resistive in comparison with the upper crust.

In Line $\mathrm{C}$ three sites were added to this line in order to develop a clearer image of the two conductive bodies previously indicated. The model presented for Line C (Fig. 3) indicate a thin conductive body east of the Central Mountain Range and a very prominent conductor extending down into the fracture zone. The conductor is much smaller in the eastern half of the Central Basin. The conductor CB is considered to be corresponding to the fracture or fault zones in the region between Sites 704 and 706 .

The vertical striping under the conductor east of the preTertiary Hatagawa tectonic line (HTL) seen in the previous model has almost disappeared in the present model. This may be due to the distortion corrections made to the data and because of the addition of supplementary data from Site 906. In this model the conductive sediment corresponding to the Yamagata basin is very shallow compared with that of the fracture zone.

\section{Discussion}

\subsection{Conductive Lower Crust (CLC)}

The lower continental crust is generally characterized by an enhanced conductivity, though there may be a considerable degree of variability (Haak and Hutton, 1986; Jones, 1992; Simpson, 1998). This conductive feature is often used to explain an aseismic lower crust, and the fluid-rich seismically weak layer of the CLC that has been incorporated into several geodynamic models (Schmeling and Marquart, 1990; Kaufman and Royden, 1994). The lower crust in the survey area is also seismically inactive (Hasegawa et al., 1991) indicating the lower crust is ductile. It is interesting how the situation is viewed through the condutivity distribution.

In Line A conductors are assumed to be limited to the upper crust if consideration is given to the trend of downward vertical striping in the models. The resistivity does not seem to decrease downward from the upper crust to the lower crust, but rather increases with depth down into the mantle to depths of at least $100 \mathrm{~km}$. The crustal resistivity structure along Line $\mathrm{A}$ is similar to that along Line B.

Except for some conductive bodies indicated by vertical striping (Fig. 3), the 1-D models also suggest an almost homogeneous resistivity distribution in the whole crust and upper mantle including the Dewa Hill (characterized by a pluton) and the Central Mountain Range. The resistivity distribution actually increases with depth under the subsurface conductor KK.

In Line $\mathrm{C}$ the profile is generally resistive with resistivities of several hundreds ohm.m except for the two conductive bodies $\mathrm{CB}$ and $\mathrm{KK}$. The present model indicates resistivities near 1,000 ohm.m at the Dewa Hill, west of CB, under the Central Mountain Range, and under the conductive body near the Pacific Coast. The resistivities on both sides of CB appear to be smaller at depth in comparison with the upper part. This may be, however, due to defects in the model as can be seen from the fit of the apparent resistivity curves.

The lower crust in the region can be probably summarized to be uniform over the whole crust or the lower crust may even be more resistive in the central part of the northeastern Japan arc as in the northern and southern parts (Ogawa, 1992; Ogawa et al., 1992). By compiling previous conductivity data, Honkura (1988) indicated that the lower crust in the northeastern Japan arc may not be regionally uniform. Our models show that the resistivity in the lower crust is in the range of several hundreds to a thousand ohm.m. This value is classified as "normal" for the lower crust by Haak and Hutton (1986).

The enhanced conductivity reported in the various tectonic situations is explained by the presence of saline fluids, black shales and/or graphite, and partial melting (Jones, 1992; Simpson, 1998). The partial melt hypothesis (Chen et al., 1996), however, could not be applicable because there are hardly found any sesimic S-wave reflectors, which suggests existence of fluid phase substance in the survey area (Hasegawa et al., 1998). Saline fluid is probably enhancing the conductivity given the premise of an interconnected network. The fluid could be trapped below the impermeable layer at the Conrad Discontinuity (Jones, 1987) resulting in a ductile lower crust without appreciable seismic activity.

How can we explain the comparably more conductive up- 


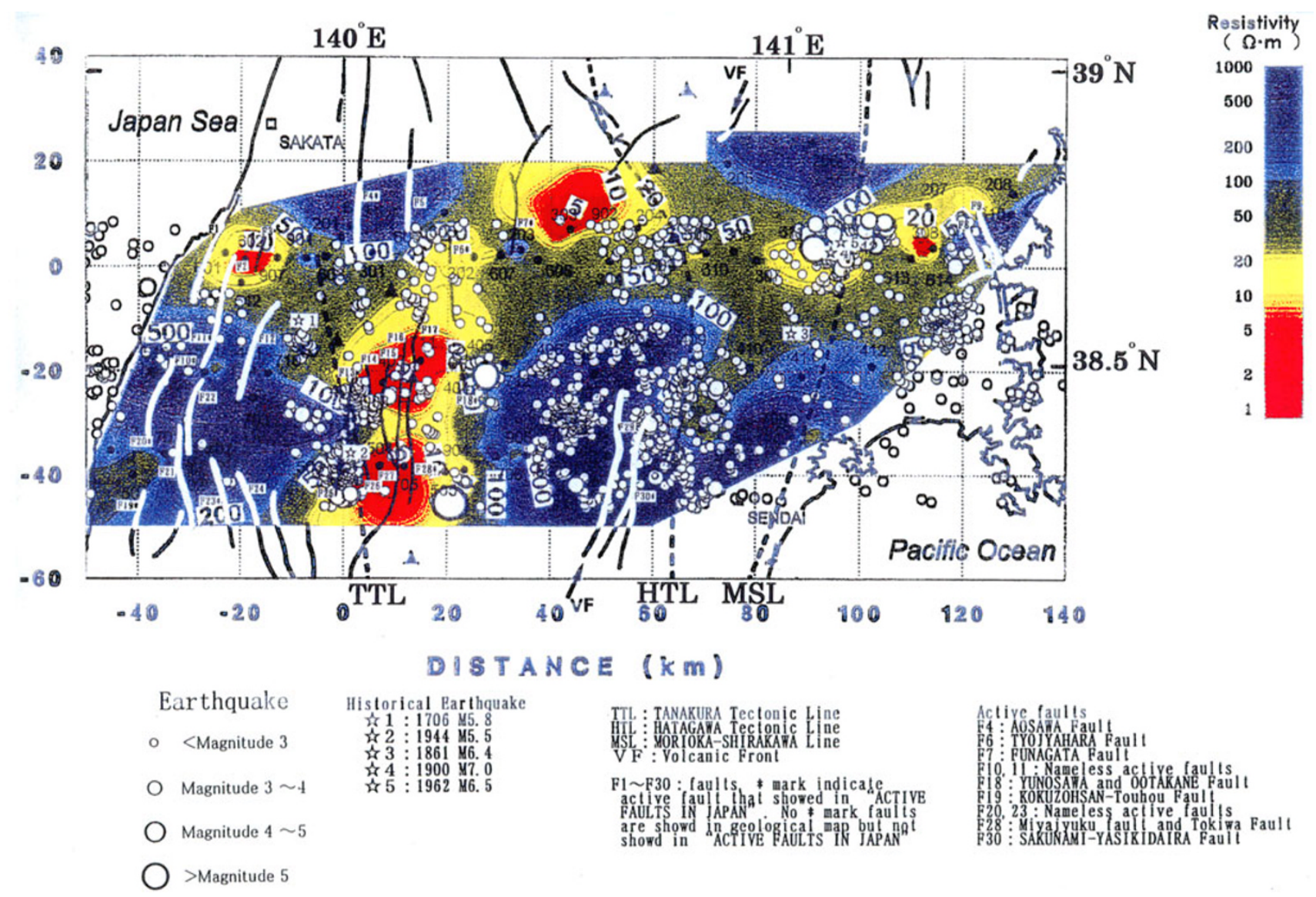

Fig. 5. Horizontal resistivity distribution at a depth of $7.5 \mathrm{~km}$, within the upper crust, and is overlain by earthquake hypocenters as determined by Tohoku University's dense seismic network and noted historical earthquakes. Solid curves attached with number F* indicate active faults (Active Fault Research Group, 1991). The solid curve with the mark F indicates active faults or lineaments (Geological Survey of Japan, 1995).

per crust in the present survey area? One very simple explanation could be built on the basis of the trapped water model of Jones (1987) and Hyndman (1988). The saline fluids are assumed to be insufficiently sealed in the midcrust in the case of the island arc. Yokokura et al. (1998) provided evidence of a breakdown of the sealing in the backarc region on the basis of seismically transparent Conrad and Moho Discontinuities in those regions.

\subsection{Seismicity}

Figure 3 illustrates the resistivity model overlain with a vertical cross section of focal positions of earthquake hypocenters within an east-west strip centered on each traverse and over a $20 \mathrm{~km}$ width. The data are from the seismic database of the Tohoku University (e.g., Hasegawa et al., 1991). In Fig. 5 are shown hypocenters of earthquakes in the upper crust with focal depths from 0 to $15 \mathrm{~km}$ located near the MT observation sites and with the resistivity distribution of a portion of the upper crust (at a depth of 7.5 $\mathrm{km})$. Historical earthquakes are indicated by star symbols ( $\lesssim$ ). Here, the horizontal resistivity distribution has been obtained through the spline interpolation of the three profiles by assuming a quasi-2-D structure. Consequently, the correlation between conductivity anomalies and tectonic units should be discussed to the extent of a spatial scale of the order of the distance between neighbouring sites. In Figs. 3 and 5 the pre-Tertiary tectonic lines, Tanakura (TTL), Hatagawa,
(HTL), and Morioka-Shirakawa (MSL) are included with the Quaternary Volcanic Front (VF) (see Fujinawa et al., 1997 and references therein for more detail).

In Figs. 3 and 5 the prominent conductive bodies observed in the backarc side are well correlated with the active faults $\left(\mathrm{F}^{*}\right)$ and geological lineaments $(\mathrm{F})$ located in this region. These include a fracture zone west of the Central Basin, the Shinjo basin (around Sites 606-203 on Line A, Fig. 1), the Yamagata basin (around Sites 405-406 on Line B, and around Sites 904-506 on Line C). Seismicity is very high in these regions indicating that the stress is being released in the fracture zones. A fluid-rich regime in the fracture zone has been suggested to weaken the crust enough to induce earthquakes.

The seismicity near the resistive Dewa Hill, west of the Central Basin, however, is very low in comparison with that found in the fracture zones even though many small faults are indicated in Figs. 3 and 5. Thus, the conductors do not always correspond to active faults. The seismicity is controlled by many factors: stress accumulation, fault strength, and regional tectonic regime. A candidate for explaining the low seismicity in the Dewa Hill region is the absence of water. In the Central Mountainous Range there is a completely different seismo-tectonics situation compared with the Dewa Hill. The resistive regions are seismically very active especially around the volcanic front (VF) while the region is assumed to be dry. 

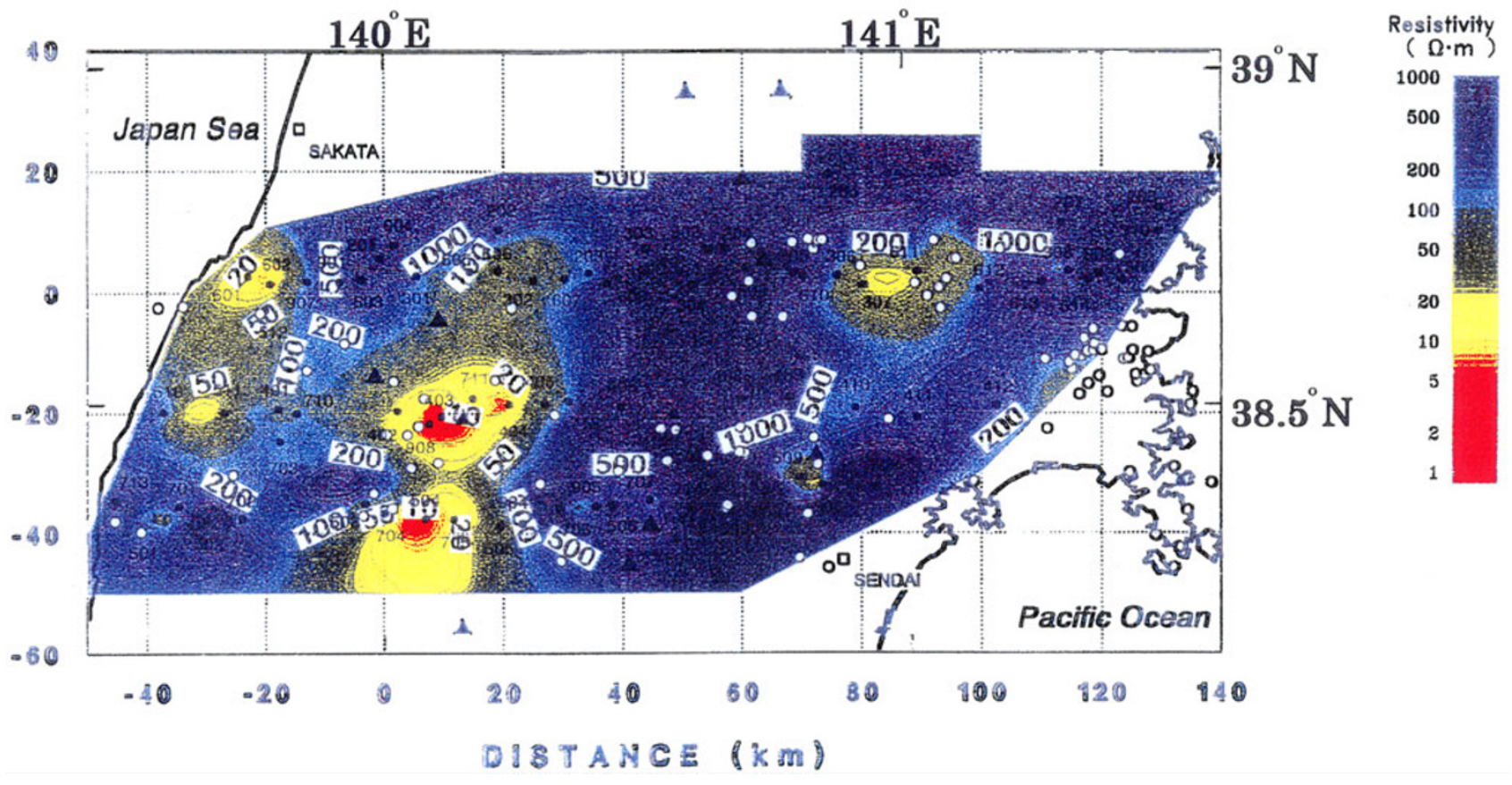

Fig. 6. Hypocentral distribution of earthquakes in the lower crust between depths 15 to $30 \mathrm{~km}$ plotted on the modeled resistivity distribution at a depth of $22.5 \mathrm{~km}$, clearly within the lower crust.

There are several isolated spots of high seismicity. We can see two moderate earthquakes occurred along the eastern edge of the conductor corresponding to Central Basin, around Site 405 on Line B and, on Line C, near Site 904 (Fig. 5). These epicenters seem to be aligned along a line that connects the active fault F7* (Funagata Fault; Active Fault Research Group, 1991), passes west of Site 203 in the north and continues along the northern tip of another geological lineament located far south of Site 706 (see Fig. 1; Geological Survey of Japan, 1995). Along this line are regions with very high resistivity contrasts with a conductive western block and a resistive eastern block. This line probably corresponds to a boundary separating the resistive Central Mountain Range from the conductive Central Basin Range. A $V p$ velocity anomaly (Zhao et al., 1992b) also supports the hypothesis. The line has not been identified before on the active fault map (Active Fault Research Group, 1991) and on geological maps (Geological Survey of Japan, 1995).

Several kilometers northwest of Site 710 there is a region with concentrated seismicity, and a moderate earthquake of magnitude 5.8 ( $\lesssim 1$ ) occurred in 1706 nearby (Fig. 5) indicating an active fault. No anomalous conductivity, however, was found in our work. Moreover, there are no traces of active faults or geological lineaments reported. The region is difficult to approach for MT measurements, and there are no means to investigate the curious seismicity occurring there except an air-borne approach.

The region around Site 612 on traverse A, about $20 \mathrm{~km}$ south of Site 206 is very active seismically. Moderate earthquakes of magnitude M 7.0 and M 6.9 have occurred in 1900 and 1962, respectively. The region can now be characterized as the eastern edge of the KK conductor (Fig. 3) and is on the Shirakawa-Morioka Line (Figs. 3 and 5). In short the relation between the seismicity (including micro-earthquake activity) and electrical conductivity turned out not to be clean-cut, suggesting that other parameters are involved in the earthquake occurrence process, depending on the tectonic situation.

It is now generally envisioned that the lower crust is ductile, with good correlation between the depths to the conductive lower crust and the upper crust seismic limits, as well as the brittle-ductile transition temperature (Adam, 1978; Meissner and Strehlau, 1982; Hyndman and Shearer, 1989; Stanley, 1989; Simpson, 1998). The Curie point depths in the observation zone estimated from the geomagnetic survey data (Okubo et al., 1985) are $10 \pm 2 \mathrm{~km}$ in the survey area indicating that the lower crust is in ductile condition. The brittle-ductile transition depth variation revealed recently by comparison of the distribution of precisely relocated micro-earthquakes with the temperature distribution calculated from the $\mathrm{P}$ wave velocity in the Central Mountain Range is shown to be in good agreement (Hasegawa et al., 1998). The resistivity is expected to provide information useful for a better estimation of temperature than has been based on the seismic velocity data (Sato et al., 1989).

Earthquakes surrounding the Miyagi-ken-hokubu earthquake in 1962 ( $\approx 5$ in Fig. 5) in the past and recent tremors in 1981 indicate a higher conductivity in this region in comparison with the surrounding sites. This situates on the boundary between the Tertiary sedimentary rock east of the Central Mountain Range and Tertiary volcanic rocks (Fig. 1). This is roughly parallel to the Sakunami-Yoshokidaira fault $\left(\mathrm{F}^{*} 3\right)$. It is suggested that this line is also a buried fault. The crossing point of this line with Line B is represented as a thin conductive region (Fig. 3).

The lower crust is generally characterized as predominantly aseismic (Fig. 6). There are, however, some differences in the seismic activity in different areas. The seismicity is extremely low in the highly resistive region. An anoma- 
lously higher seismicity characterized by the low-frequency earthquakes can also be observed near the geothermal area around Sites 204 and 305. These sites are near the Quaternary volcanoes Komagatake and Onikobe. Hasegawa et al. (1998) indicates that these low-frequency earthquakes are related to magma activity.

\section{Conclusions}

Wide-band MT observations have been conducted at 86 sites along three transects in the central part of the northeastern Japan arc. The magnetotelluric impedance tensors were corrected for possible 3-D distortion effects including static-shifts by using TEM data. 2-D models were obtained using the GRRI inversion algorithm to refine the previously reported one. These profiles show that:

1) The 2-D resistivity models at three transects are grossly similar justifying 2-D assumptions in this region.

2) The upper crust is thought to be wet.

3) In the major fracture zones at the west and east side of the Central Basin, there is a good correlation between resistivity contrasts, faults or geological lineaments and seismicity.

4) The Central Mountain Range and Dewa Hill are characterized both by resistive bodies suggesting the stress gradient in the direction of subduction.

5) Active seismicity around the boundaries of the Central Basin and the Central Mountain Range may be due to a buried fault.

6) Many of the faults associated with scarce seismicity are characterized by higher resistivities.

Acknowledgments. The authors express their sincere thanks to Drs. Hiroshi Takahashi, Shigetsugu Uyehara, Gensuke Endo (late), and Prof. Sachio Nabetani for their constant encouragement. Thanks are also expressed to Profs. Nobuaki Niizuma, and Yoshihiro Suzuki for valuable discussions and suggestions, and to the many organizations and institutes that helped us to conduct experiments. We thank greatly Prof. John Weaver, Dr. Fiona Simpson and one anonymous reviewer for numerous valuable comments and helpful suggestions on the original and the revised manuscript. The preparation of the manuscript was helped by Ms. Yumiko Yamauchi and Mr. Wu Yuesheng. The Science and Technology Agency Japan funded the study for the Promotion of Surveys and Research on Earth Science and Technology and Ocean Development.

\section{References}

Active Fault Research Group (rev. ed.), Active Faults in Japan, 437 pp., University of Tokyo Press, Tokyo, 1991.

Adam, A., Geothermal effects in the formation of electrically conducting zones and temperature distribution in the earth, Phys. Earth Planet. Inter., 17, 21-28, 1978

Calvert, A., E. W. Sawyer, W. J. Davis, and J. N. Ludden, Archean subduction inferred from seismic images of a mantle structure in the Superior Province, Nature, 375, 670-674, 1995.

Chen, L., J. R. Booker, A. G. Jones, N. Wu., M. J. Unsworth, W. We, and H. Tan, Electrically conductive crust in Southern Tibet from INDEPTH magnetotelluric surveying, Science, 274, 1694-1696, 1996.

Fujinawa, Y., N. Kawakami, T. H. Asch, M., Uyeshima, and Y. Honkura, Studies of the Georesistivity structure in the central part of the northeastern Japan Arc, J. Geomag. Geoelectr., 49, 1601-1617, 1997.
Gamble, T. D., W. M. Goubau, and J. Clarke, Magnetotellurics with a remote reference, Geophysics, 44, 53-68, 1979.

Geological Survey of Japan (ed.), Geological Map of Japan 1:1,000,000, 3rd Edition, CD-ROM Version, Digital Geoscience Map G-1, Geological Survey of Japan, 1995.

Groom, R. W. and R. C. Bailey, Decomposition of magnetotelluric impedance tensors in the presence of local three-dimensional galvanic distortions, J. Geophys. Res., 94, 1913-1925, 1989.

Groom, R. W. and R. C. Bailey, Analytical investigations of the effects of near-surface three-dimensional galvanic scatters on MT tensor decomposition, Geophysics, 56, 496-518, 1991.

Groom, R. W., R. D. Kurtz, A. G. Jones, and D. E. Boerner, A quantitative methodology to extract regional magnetotelluric impedances and determine the dimension of the conductivity structure, Geophys. J. Int., 115, 1095-1118, 1993.

Haak, V. and V. R. S. Hutton, Electrical resistivity in continental lower crust, in The Nature of the Lower Continental Crust, edited by J. B. Dawson, D. A. Carswell, J. Hall, and K. H. Wedepohl, Geol. Soc. London, Spe. Publ., 24, pp. 35-49, 1986.

Hasegawa, A., D. Zhao, S. Hori, A. Yamamoto, and S. Horiuchi, Deep structure of the northeastern Japan arc and its relationship to seismic and volcanic activity, Nature, 352, 682-689, 1991

Hasegawa, A., A. Yamamoto, N. Umino, and S. Miura, Seismic activity and deformation process of the overriding plate in the northeastern Japan subduction zone, 1999 (to be submitted).

Hasemi, A., H. Ishii, and A. Takagi, Fine structure beneath the Tohoku District, Northeastern Japan arc, as derived by an inversion of P-wave arrival times from local earthquakes, Tectonophysics, 101, 245-265, 1984.

Honkura, Y., Electrical conductivity structure in the upper mantle and its implications for the origin of magma, Kazan, 2(33), 203-212, 1988 (in Japanese).

Horiuchi, S., H. Ishii, and A. Takagi, Two-dimensional depth structure of the crust beneath the Tohoku District, the northeastern Japan arc, I, Method and Conrad discontinuity, J. Phys. Earth, 30, 47-69, 1982a.

Horiuchi, S., A. Yamamoto, S. Ueki, K. Tachibana, T. Kono, and A. Takagi, Two-dimensional depth structure of the crust beneath the Tohoku District, the northeastern Japan arc, 2, Moho discontinuity and P-wave velocity, J. Phys. Earth, 30, 71-86, 1982 b.

Hyndman, R. D., Dipping seismic reflectors, electrically conductive zones, and trapped water in the crust over a subducting plate, J. Geophys. Res. 93, 13,391-13,405, 1988.

Hyndman, R. D. and P. M. Shearer, Water in the lower continental crust: modelling magnetotelluric and seismic reflection results, Geophys. J. Int., 98, 343-365, 1989.

Jiracek, G. R., Near-surface and topographic distortions in electromagnetic induction, Surv. Geophys., 11, 163-203, 1990.

Jones, A. G., MT and reflection; and essential combination, Geophys. J. R Astr. Soc., 89, 7-18, 1987.

Jones, A. G., Electrical conductivity of the continental lower crust, in Continental Lower Crust, edited by D. M. Fountain, R. J. Arculus, and R. W. Kay, Elsevier, New York, 1992.

Kaufman, P. S. and L. H. Royden, Lower crustal flow in an extensional setting: Constraints from the Halloran Hills region, eastern Mojave Desert, California, J. Geophys. Res., 99, 15,723-15,739, 1994.

Kawakami, N., Y. Fujinawa, T. H. Asch, and S. Takasugi, Local three dimensional galvanic distortions in the central part of northeastern Japan, J. Geomag. Geoelectr., 49, 1387-1400, 1997.

Kawakami N., Y. Fujinawa, J. Inoue, and T. H. Asch, Local Galvanic Distortions in the Central Part of North-eastern Japan (Part 2), Earth Planets Space, 1998 (to be submitted)

Kimura, T., I. Hayami, and S. Yoshida, Geology of Japan, University of Tokyo Press, 1991.

Lee, K. H., K. Yamane, and S. Takasugi, A new 2-D inversion scheme for magnetotelluric data using a modified RRI method, in Proceedings of the World Geothermal Congress, Vol. 2, pp. 915-920, 1995.

Meju, M. A., Joint inversion of TEM and distorted MT soundings, Some effective practical considerations, Geophysics, 61(1), 56-65, 1996.

Meissner, R. and J. Strehlau, Limits of stresses in continental crusts and their relation to the depth frequency distribution of shallow earthquakes, Tectonics, 1, 73-89, 1982.

Nabetani, S., K. Maekawa, and K. Uchida, Conductivity structure of crust and mantle in the Northeastern Japan prospected by MT and GEMIT method, 1. East to west section along $40^{\circ} 40^{\prime} \mathrm{N}$ traverse, Sci. Rep. Hirosaki Univ., 39, 37-46, 1992. 
Obara, K., A. Hasegawa, and A. Takagi, Three-dimensional P and S wave velocity structure beneath the northeastern Japan arc, J. Seismol. Soc. Japan., 39, 201-215, 1986

Ogawa, Y., Deep crustal resistivity structure revealed by sideband magnetotellurics-Tohoku and Hokkaido region, Ph.D. Thesis, University of Tokyo, 320 pp., 1992.

Ogawa, Y., Y. Mitsuhata, and S. Tokokura, Results of wide band magnetotelluric transect across the northern Tohoku district-Akita-Iwaizumi-profile, in Proc. 1992, Conductivity Anomaly Symposium, pp. 124-132, 1992.

Okubo, Y., H. Tsu, and K. Ogawa, Curie point depths of Japan, in Geothermal Resources Council Transactions, 9-part II, pp. 35-39, 1985.

Sato, H., I. S. Sacks, and T. Murase, The use of laboratory velocity data for estimating temperature and partial melt fraction in the low velocity zone: comparison with heat flow and electrical conductivity studies, $J$. Geophys. Res., 94, 5689-5704, 1989.

Schmeling, H. and G. Marquart, A mechanism for crustal thinning without lateral extension, Geophys. Res. Lett., 17, 2417-2420, 1990.

Simpson, F., Stress and seismicity in the lower-continental rust: a challenge to simple ductility and implication for electrical conductivity mechanisms, in The 14th Workshop on Electromagnetic Induction in the Earth (Abstract), pp. 215-228, 1998.

Smith, J. T. and J. R. Booker, Rapid inversion of two and three dimensional magnetotelluric data, J. Geophys. Res., 96, 3905-3922, 1991.

Spies, B. R. and D. E., Eggers, The use and misuse of apparent resistivity in electromagnetic methods, Geophysics, 51(7), 1462-1471, 1986.

Stanley, W. D., Comparison of geoelectrical/tectonic models for suture zones in the western U.S.A. and eastern Europe: are black shales a possible source of high conductivities?, Phys. Earth Planet. Inter., 53, 228-238,
1989

Sternberg, B. K., J. C. Washburne, and L. Pellerin, Correction for the static shift in magnetotelluric using transient electromagnetic soundings, Geophysics, 53, 1459-1468, 1988.

Tournerie, B. and M. Chouteau, Deep conductivity structure in Abitibi, Canada, using long dipole magnetotelluric measurements, Geophys. Res. Lett., 25, 2327-2320, 1998.

Umino. N. and A. Hasegawa, On the two-layered structure of a deep seismic plane in the northeastern Japan arc, J. Seismol. Soc. Japan., 28, 125-139, 1975.

Yamane, K., S. Takasugi, and K. H. Lee, A new magnetotelluric inversion scheme using generalized RRI method and case studies, Geophysics, 35, 209-213, 1996.

Yokokura, T., T. Miyazaki, Y. Watanabe, and T. Urabe, A preliminary experiment towards deep seismic profiling GSJ90-1 Hidaka, Hokkaido, Zisin, 2(45), 145-156, 1992

Yokokura, T., T. Miyazaki, N. Kano, and K. Yamaguchi, Lower crustal and sub-crustal reflectors beneath the southern Kit akami area, in 1998 Japan Earth and Planetary Science Joint Meeting (Abstract), p. 363, 1998.

Zhao, D., S. Horiuchi, and A. Hasegawa, Seismic velocity structure of the crust beneath the Japan islands, Tectonophysics, 212, 289-301, 1992a.

Zhao, D., A. Hasegawa, and S. Horiuchi, Tomographic imaging of P and W wave velocity structure beneath Northeastern Japan, J. Geophys. Res., 97, 19,909-19,928, 1992b

Y. Fujinawa (e-mail: fujinawa@bosai.go.jp), N. Kawakami, J. Inoue, T. H. Asch, S. Takasugi, and Y. Honkura 